\title{
Structure and nonlinear optical properties of novel transparent glass-ceramics based on $\mathrm{Co} 2+: \mathrm{ZnO}$ nanocrystals
}

Article in Laser Physics Letters · May 2016

Impact Factor: $2.46 \cdot$ DOI: 10.1088/1612-2011/13/5/055803

READS

49

12 authors, including:

\section{Pavel Loiko}

KTH Royal Institute of Technology 92 PUBLICATIONS 372 CITATIONS

SEE PROFILE

\section{Vladimir Vitkin}

ITMO University

10 PUBLICATIONS 2 CITATIONS

SEE PROFILE

\section{Olga Dymshits}

Vavilov State Optical Institute

95 PUBLICATIONS 574 CITATIONS

SEE PROFILE

\section{K.V. Yumashev}

Belarusian National Technical University

291 PUBLICATIONS 2,511 CITATIONS

SEE PROFILE 


\title{
Structure and nonlinear optical properties of novel transparent glass-ceramics based on $\mathrm{Co}^{2+}: \mathrm{ZnO}$ nanocrystals
}

\author{
P A Loiko ${ }^{1}$, O S Dymshits ${ }^{2}$, V V Vitkin ${ }^{3}$, N A Skoptsov ${ }^{1}$, A A Zhilin², \\ D V Shemchuk' ${ }^{2}$ M Ya Tsenter ${ }^{2}$, K V Bogdanov ${ }^{3}$, A M Malyarevich ${ }^{1}$, \\ I V Glazunov ${ }^{1}$, X Mateos ${ }^{4}$ and K V Yumashev ${ }^{1}$ \\ ${ }^{1}$ Center for Optical Materials and Technologies, Belarusian National Technical University, \\ 65/17 Nezavisimosti Ave., Minsk 220013, Belarus \\ 2 NITIOM S.I. Vavilov State Optical Institute, \#36, Babushkina Str., St Petersburg 192171, Russia \\ 3 ITMO University, 49 Kronverkskiy pr., Saint-Petersburg 197101, Russia \\ ${ }^{4}$ Física i Cristal-lografia de Materials i Nanomaterials (FiCMA-FiCNA), Universitat Rovira i Virgili \\ (URV), Campus Sescelades, c/ Marcel-lí Domingo, s/n., Tarragona E-43007, Spain \\ E-mail: kinetic@tut.by
}

Received 27 August 2015, revised 22 March 2016

Accepted for publication 23 March 2016

Published 8 April 2016

\begin{abstract}
Transparent glass-ceramics (GCs) based on $\mathrm{Co}^{2+}: \mathrm{ZnO}$ nanocrystals (mean diameter, $11 \mathrm{~nm}$ ) are synthesized on the basis of cobalt-doped glasses of the $\mathrm{K}_{2} \mathrm{O}-\mathrm{ZnO}-\mathrm{Al}_{2} \mathrm{O}_{3}-\mathrm{SiO}_{2}$ system. For these GCs, the absorption band related to the ${ }^{4} \mathrm{~A}_{2}\left({ }^{4} \mathrm{~F}\right) \rightarrow{ }^{4} \mathrm{~T}_{1}\left({ }^{4} \mathrm{~F}\right)$ transition of $\mathrm{Co}^{2+}$ ions in tetrahedral sites spans until $\sim 1.73 \mu \mathrm{m}$. Saturation of the absorption is demonstrated at $1.54 \mu \mathrm{m}$, with a saturation fluence $F_{\mathrm{s}}=0.8 \pm 0.1 \mathrm{Jcm}^{-2}\left(\sigma_{\mathrm{GSA}}=1.7 \pm 0.2 \times 10^{-19} \mathrm{~cm}^{2}\right)$ and a recovery time of $890 \pm 10 \mathrm{~ns}$. Passive Q-switching of an Er,Yb:glass laser is realized with the synthesized GCs. This laser generated $0.37 \mathrm{~mJ} / 100 \mathrm{~ns}$ pulses at $1.54 \mu \mathrm{m}$. The developed GCs are promising as saturable absorbers for 1.6-1.7 $\mu \mathrm{m}$ crystalline erbium lasers.
\end{abstract}

Keywords: glass-ceramics, cobalt, zinc oxide, erbium laser, Q-switching

(Some figures may appear in colour only in the online journal)

\section{Introduction}

Erbium $\left(\mathrm{Er}^{3+}\right)$ ions are attractive due to their eye-safe emission around $1.5 \mu \mathrm{m}$ related to the ${ }^{4} \mathrm{I}_{13 / 2} \rightarrow{ }^{4} \mathrm{I}_{15 / 2}$ transition. Pulsed erbium lasers are of practical importance for rangefinding, environmental sensing, aerial navigation, telecom applications and laser surgery.

There are two main schemes for the excitation of $\mathrm{Er}^{3+}$ ions. The first one is codoping the host with the $\left(\mathrm{Er}^{3+}, \mathrm{Yb}^{3+}\right)$ couple. $\mathrm{Yb}^{3+}$ ions can be efficiently pumped at $\sim 0.98 \mu \mathrm{m}$ by commercial InGaAs laser diodes; the subsequent excitation of $\mathrm{Er}^{3+}$ ions occurs due to the energy-transfer (ET), ${ }^{2} \mathrm{~F}_{5 / 2}$ $\left(\mathrm{Yb}^{3+}\right) \rightarrow{ }^{4} \mathrm{I}_{11 / 2}\left(\mathrm{Er}^{3+}\right)$. However, this scheme suffers from a strong up-conversion related to the ET process (that generates a lot of unwanted heat and limits the laser efficiency). It also requires careful optimization of dopant concentrations, thermal and thermo-optical properties and vibrational frequencies of the host. State-of-the-art materials for $\left(\mathrm{Er}^{3+}, \mathrm{Yb}^{3+}\right)$ codoping are phosphate glasses providing very high efficiencies of the ET but possessing very poor thermal properties [1]. Thus, several crystalline materials were proposed as an alternative for the glass in terms of thermo-mechanical properties, however, only a few of them, basically borates such as $\mathrm{REAl}_{3}\left(\mathrm{BO}_{3}\right)_{4}$ where $\mathrm{RE}=\mathrm{Y}, \mathrm{Gd}$ or $\mathrm{Lu}$ [2-4] can compete with phosphate glasses in terms of ET efficiency. In addition, they provide low thermo-optic aberrations [5].

Phosphate glass [6,7] and crystalline borate [8] lasers can be efficiently Q-switched by $\mathrm{Co}: \mathrm{MgAl}_{2} \mathrm{O}_{4}$ spinel single crystals using the saturable absorption related to the ${ }^{4} \mathrm{~A}_{2}\left({ }^{4} \mathrm{~F}\right) \rightarrow{ }^{4} \mathrm{~T}_{1}\left({ }^{4} \mathrm{~F}\right)$ transition of tetrahedrally coordinated 
$\mathrm{Co}^{2+}$ ions. Indeed, the emission wavelengths of these lasers $(1.54 \ldots 1.60 \mu \mathrm{m})$ perfectly match the absorption band of Co: $\mathrm{MgAl}_{2} \mathrm{O}_{4}$ single crystals.

The second scheme for the excitation of Er lasers is the so-called resonant (in-band) pumping. Such a direct excitation to the upper laser level of $\mathrm{Er}^{3+},{ }^{4} \mathrm{I}_{13 / 2}$, can be achieved by Er fiber lasers or InGaAsP/InP laser diodes emitting at $\sim 1.5 \mu \mathrm{m}$. Several high-energy crystalline in-band-pumped Er lasers were recently realized emitting typically at wavelengths longer than $1.6 \mu \mathrm{m}$ [9-11]. In particular, the Er:YAG crystal provides a laser emission at $1645 \mathrm{~nm}$ [11], where the use of the $\mathrm{Co}: \mathrm{MgAl}_{2} \mathrm{O}_{4}$ single crystal is no longer efficient due to an increased saturation fluence. Thus, the search for novel saturable absorbers (SAs) operating in the 1.6-1.7 $\mu \mathrm{m}$ spectral range is of high importance for efficient Q-switching of Er crystalline lasers.

Transparent $\mathrm{Co}^{2+}$-doped spinel-based nanophase glassceramics (GCs) were recognized as a good alternative to $\mathrm{Co}: \mathrm{MgAl}_{2} \mathrm{O}_{4}$ single crystals. They typically contain nanosized crystals of $\mathrm{Mg}$-spinel $\mathrm{MgAl}_{2} \mathrm{O}_{4}$ or gahnite $\mathrm{ZnAl}_{2} \mathrm{O}_{4}$ [12, 13] or $\mathrm{\gamma}^{-} \mathrm{Ga}_{2} \mathrm{O}_{3}$ [14] with $\mathrm{Co}^{2+}$ ions incorporated in sites with tetrahedral symmetry. As compared with single crystals, GCs offer an easier synthesis technique based on the standard glass melt-quenching method with a subsequent heat-treatment; GCs provide relatively low scattering losses $\left(\alpha_{\text {loss }}<0.1 \mathrm{~cm}^{-1}\right.$ at $\sim 1.6 \mu \mathrm{m}$ ) [12]. Synthesis of novel GCs wherein the local environment of $\mathrm{Co}^{2+}$ ions could provide a lower ligand field than in spinel crystals, which would result in a red-shift of $\mathrm{Co}^{2+}$ spectral bands, can solve the above-mentioned problem of the lack of long-wavelength SAs.

In the present letter, we report on the synthesis, structure and nonlinear optical properties of novel transparent GCs containing nanosized $\mathrm{Co}^{2+}: \mathrm{ZnO}$ crystals suitable for passive Q-switching of crystalline erbium lasers emitting at 1.6-1.7 $\mu \mathrm{m}$.

\section{Synthesis of glass-ceramics}

The glass with the composition (wt $\%$ ) $15 \mathrm{~K}_{2} \mathrm{O}-30 \mathrm{ZnO}-$ $16 \mathrm{Al}_{2} \mathrm{O}_{3}-39 \mathrm{SiO}_{2}[15,16]$ was doped with 0.05 or $0.1 \mathrm{wt} \%$ $\mathrm{CoO}$. The starting materials for the glass preparation included reagent grade $\mathrm{K}_{2} \mathrm{CO}_{3}, \mathrm{ZnO}, \mathrm{Al}_{2} \mathrm{O}_{3}$ and $\mathrm{SiO}_{2}$. The appropriate components were carefully mixed and glasses $200 \mathrm{~g}$ in weight were melted in platinum crucibles in a laboratory electric furnace at $1590{ }^{\circ} \mathrm{C}$ for $3 \mathrm{~h}$ with stirring, cast onto a cold metal plate and annealed at $550{ }^{\circ} \mathrm{C}$ in an electric furnace. The temperature of secondary heat-treatments was ranged from 650 to $750{ }^{\circ} \mathrm{C}$, the heating rate was $5^{\circ} \mathrm{C}$ per min; the heattreatment duration was $2-24 \mathrm{~h}$. The initial glasses were transparent and violet-blue colored, after the heat-treatment, they remained transparent while their color changed to blue-green.

\section{Results and discussion}

\subsection{Structural study}

Phase assemblages of initial and heat-treated glasses were identified using x-ray powder diffraction technique (using a

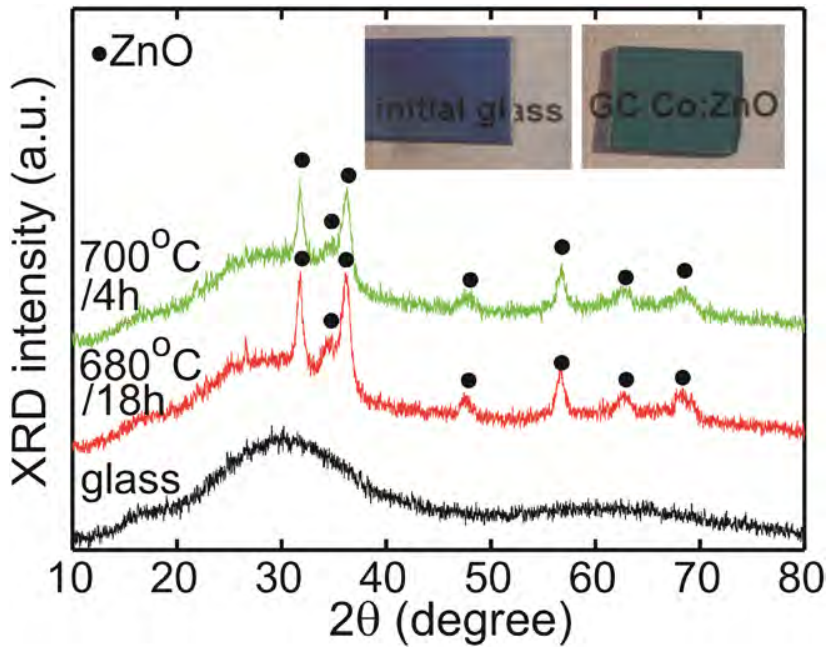

Figure 1. XRD patterns of initial and heat-treated glasses doped with $0.05 \mathrm{wt} \% \mathrm{CoO}$, inset: images of the polished samples lying on the paper with the typed text 'initial glass' and ' $\mathrm{GC} \mathrm{Co:ZnO'.}$

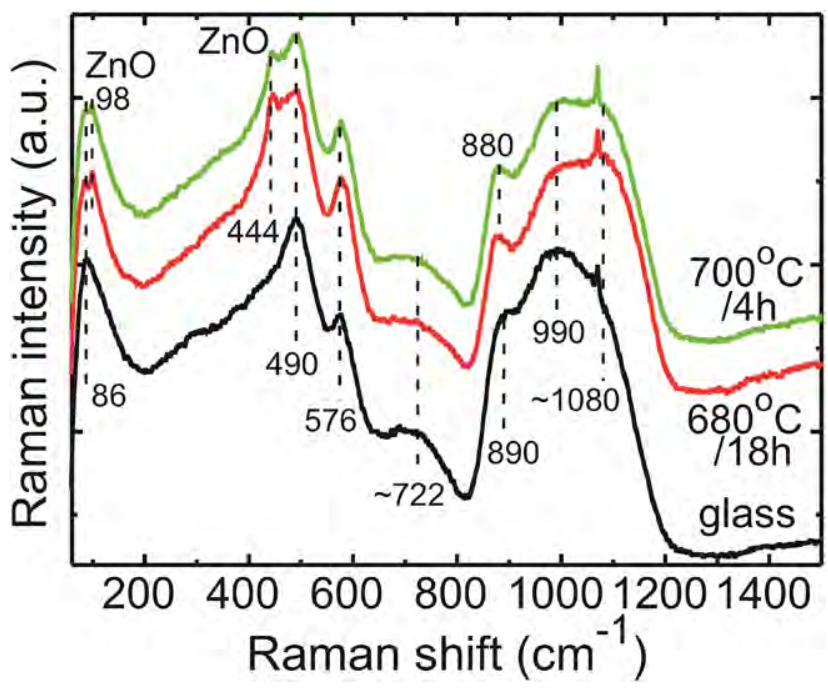

Figure 2. Raman spectra of initial and heat-treated glasses doped with $0.05 \mathrm{wt} \% \mathrm{CoO}$. The excitation wavelength is $488 \mathrm{~nm}$.

Shimadzu 6000 diffractometer, $\mathrm{Cu} \mathrm{K} \alpha$ radiation with a $\mathrm{Ni}$ filter). The detected $x$-ray diffraction (XRD) patterns of the initial glass and GCs are shown in figure 1 . The mean crystal sizes were estimated from the broadening of the $\mathrm{x}$-ray peaks according to [17]:

$$
D=K \lambda / \Delta(2 \theta) \cos \theta,
$$

where $\lambda$ is the $\mathrm{x}$-ray radiation wavelength, $\theta$ is the diffraction angle, $\Delta(2 \theta)$ is the width of the peak at half of its maximum, and $K$ is a constant that was assumed to be 1 [17]. The error of the crystal size estimation was $\sim 5 \%$ for the crystal sizes of $2-15 \mathrm{~nm}$.

The initial glasses were $\mathrm{x}$-ray amorphous, figure 1 . The heattreatments in the temperature range of $680-700{ }^{\circ} \mathrm{C}$ resulted in crystallization of $\mathrm{ZnO}$ nanocrystals with a hexagonal wurtzite structure, with all zinc and oxygen ions with tetrahedral coordination [15]. Their mean sizes were about $11 \mathrm{~nm}$.

Phase transformations in the initial glasses as a result of heat-treatments were also studied by Raman spectroscopy, 

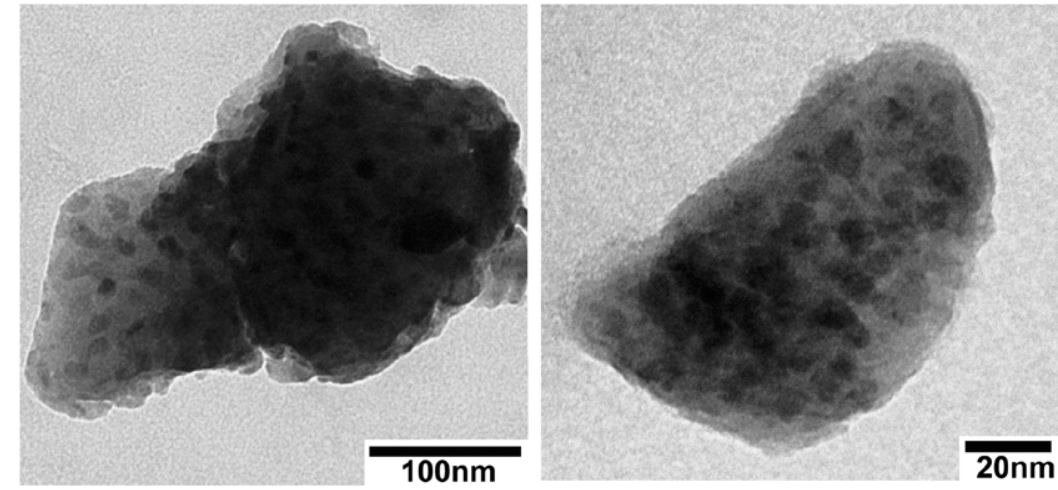

Figure 3. TEM images of the GC doped with $0.1 \mathrm{wt} \% \mathrm{CoO}$ and prepared by heat-treatment at $700{ }^{\circ} \mathrm{C}$ for $24 \mathrm{~h}$.

figure 2. The Raman spectra were recorded in backscattering geometry by using an 'InVia' (Renishaw, England) MicroRaman spectrometer equipped with the multichannel detector cooled down to $-70{ }^{\circ} \mathrm{C}$. The $\mathrm{Ar}^{+}$laser line of $488 \mathrm{~nm}$ was employed as an excitation source. A Leica $50 \times(\mathrm{NA}=0.75)$ objective was used for illuminating the sample and the scattered light was collected by the same objective. An edge filter was placed before the spectrograph entrance slit. A spatial resolution of $2 \mathrm{~cm}^{-1}$ was obtained. The acquisition time was $60 \mathrm{~s}$.

The Raman spectrum of the initial glass consists of a highfrequency envelope with maxima at 890,990 and $1080 \mathrm{~cm}^{-1}$, the main band with peaks at 490,576 and $722 \mathrm{~cm}^{-1}$, and the boson peak at $\sim 86 \mathrm{~cm}^{-1}$. A similar Raman spectrum with slightly different frequencies of peaks was obtained by Du et al [18] for a glass of the same system with a similar composition $15 \mathrm{~K}_{2} \mathrm{O}-25 \mathrm{ZnO}-15 \mathrm{Al}_{2} \mathrm{O}_{3}-45 \mathrm{SiO}_{2}$ (in $\mathrm{mol} \%$ ). After the heat-treatment of the initial glass, the shape of the highfrequency envelope in its spectrum changes due to the intensity increase of the band at $1080 \mathrm{~cm}^{-1}$. Two new sharp peaks appear at 98 and $444 \mathrm{~cm}^{-1}$. They can be assigned to the $E_{2}$ (low) and $E_{2}$ (high) modes of wurtzite $\mathrm{ZnO}$ crystals, respectively [18-20]. The $E_{2}$ (low) mode is related to the vibration of the heavy $\mathrm{Zn}$ sublattice and the $E_{2}$ (high) mode involves only oxygen atoms [19]. The intensity enhancement of the band at $1080 \mathrm{~cm}^{-1}$ of the high-frequency envelope can be explained by the increased connectivity of the aluminosilicate network caused by the $\mathrm{ZnO}$ crystallization. The initial glass composition in mol\% was $12 \mathrm{~K}_{2} \mathrm{O}-28 \mathrm{ZnO}-12 \mathrm{Al}_{2} \mathrm{O}_{3}-48 \mathrm{SiO}_{2}$. In the assumption that all the $\mathrm{ZnO}$ participates in the crystallization, the residual glass composition can be expressed as $16.7 \mathrm{~K}_{2} \mathrm{O}-16.7 \mathrm{Al}_{2} \mathrm{O}_{3}-66.6 \mathrm{SiO}_{2}$, i.e. $\mathrm{K}_{2} \mathrm{O} \cdot \mathrm{Al}_{2} \mathrm{O}_{3} \cdot 4 \mathrm{SiO}_{2}$, or $\mathrm{KAlSi}_{2} \mathrm{O}_{6}$, which matches the composition of mineral leucite. We are not aware of the existence of the spectrum of a glass with leucite composition in the literature, however, the spectrum of amorphous leucite obtained at high pressure is known [21] and its high-frequency envelope is consistent with those of the glass-ceramics obtained in this work. The Raman spectra of the $\mathrm{SiO}_{2}-\mathrm{KAlSi}_{3} \mathrm{O}_{8}$ glass series [22] also demonstrate similar features. It is unlikely that the residual glass having potassium cations in sufficient quantity to charge balance the four-fold coordinated $\mathrm{Al}^{3+}$ contains a significant number of non-bridging oxygen atoms. On this basis, it is inferred that high-frequency features in the glass-ceramic spectrum result primarily from the antisymmetric-stretching modes of $\mathrm{O}$ atoms and network-forming cations in the 3D aluminosilicate framework [23].

The structure of the glass-ceramics was also studied by transmission electron microscopy (TEM). For TEM studies, finely powdered samples were dispersed in ethanol. The microscope used was a JEOL TEM-1011 (100kV acceleration voltage, $0.4 \mathrm{~nm}$ point resolution). The sample obtained by heat-treatment at $700{ }^{\circ} \mathrm{C}$ for $24 \mathrm{~h}$ and containing $\mathrm{ZnO}$ nanocrystals, as determined by the XRD analysis, was investigated. The TEM images (figure 3) reveal a near-uniform distribution of inhomogeneous dark regions. We refer these regions to the nanosized $\mathrm{ZnO}$ crystals located in the residual glassy phase. The average size of nanocrystals $D_{\text {TEM }}$ is $11.2 \pm 0.4 \mathrm{~nm}$ that agrees well with $D_{\mathrm{XRD}}(\sim 11 \mathrm{~nm})$; and their shape is nearly spherical.

\subsection{Optical absorption}

For the optical absorption measurements, we used Varian CARY-5000 spectrophotometer. The samples were plates polished down to $\sim 0.4 \mathrm{~mm}$.

The absorption spectra of the initial glass and glassceramics are shown in figure 4. The spectrum of the initial glass is typical for absorption of $\mathrm{Co}^{2+}$ ions in aluminosilicate glasses [24, 25]. The spectrum contains two broad structured absorption bands in the $470-720 \mathrm{~nm}\left(21000-14000 \mathrm{~cm}^{-1}\right)$ and $1100-1700 \mathrm{~nm}\left(9000-5800 \mathrm{~cm}^{-1}\right)$ ranges with local peaks at $525 / 590 / 640 \mathrm{~nm}$ and $1235 / 1455 / 1660 \mathrm{~nm}$. This type of the spectrum is characteristic of $\mathrm{Co}^{2+}$ ions in a distorted tetrahedral coordination in silicate glasses [26, 27]. However, the relatively low intensity of the absorption bands suggests the contribution of $\mathrm{Co}^{2+}$ ions in octahedral and possibly in 5-fold coordinated sites $[24,28,29]$. Their absorption at $\sim 525 \mathrm{~nm}$ coincides with one of the peaks related to the absorption of $\mathrm{Co}^{2+}$ ions in a distorted tetrahedral coordination [24, 28, 29].

Crystallization of $\mathrm{ZnO}$ is accompanied by a change in the absorption spectrum. The UV absorption edge of the initial glass shifts to the visible due to the crystallization of $\mathrm{ZnO}$; its position depends on the heat-treatment applied. The intensity of both absorption bands continuously increases and their shape is changed. In the visible part of the spectrum, there is a gradual reduction of absorption at $\sim 525 \mathrm{~nm}$, an appearance of a shoulder at $\sim 565 \mathrm{~nm}$, a shift of the absorption bands at 590 and $640 \mathrm{~nm}$ to 607 and $643 \mathrm{~nm}$, respectively, and an increase 


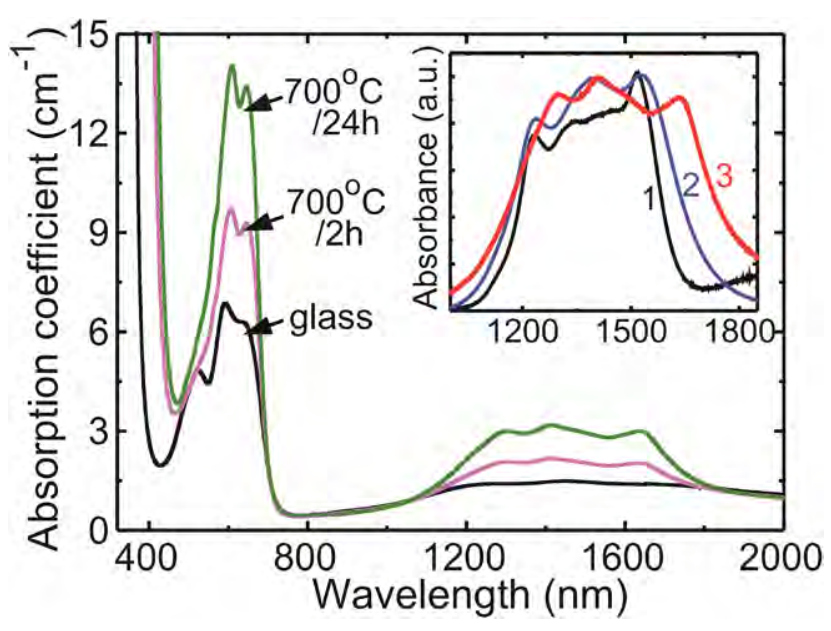

Figure 4. Absorption spectra of the initial glass and $\mathrm{GC}$ doped with $0.1 \mathrm{wt} \% \mathrm{CoO}$, inset: absorption band related to the ${ }^{4} \mathrm{~A}_{2}\left({ }^{4} \mathrm{~F}\right) \rightarrow{ }^{4} \mathrm{~T}_{1}\left({ }^{4} \mathrm{~F}\right)$ transition of $\mathrm{Co}^{2+}$ ions in tetrahedral sites in (1) $\mathrm{Co}: \mathrm{MgAl}_{2} \mathrm{O}_{4}$ single-crystal and $\mathrm{GC}$ containing (2) $\mathrm{Co}: \mathrm{MgAl}_{2} \mathrm{O}_{4}$ and (3) $\mathrm{Co:ZnO}$ nanocrystals.

of their intensity. The broad band in the $1.2-1.7 \mu \mathrm{m}$ range becomes narrower; the peaks become more distinct than in the spectrum of the initial glass. This broad band is composed of four separate peaks located at $\sim 1.29,1.42,1.49$ and $1.64 \mu \mathrm{m}$.

The absorption bands observed for GCs coincide well with the ones for $\mathrm{Co}^{2+}: \mathrm{ZnO}[30,31]$ and they can be ascribed to the $\mathrm{d}-\mathrm{d}$ transitions of $\mathrm{Co}^{2+}$ ions with $3 \mathrm{~d}^{7}$ high-spin configuration in a tetrahedral ligand field formed by neighboring oxygen ions in $\mathrm{ZnO}$ nanocrystals. Three absorption peaks in the visible range are assigned as ${ }^{4} \mathrm{~A}_{2}(\mathrm{~F}) \rightarrow{ }^{2} \mathrm{E}(\mathrm{G}),{ }^{4} \mathrm{~A}_{2}(\mathrm{~F}) \rightarrow{ }^{4} \mathrm{~T}_{1}(\mathrm{P})$, and ${ }^{4} \mathrm{~A}_{2}(\mathrm{~F}) \rightarrow{ }^{2} \mathrm{~A}_{1}(\mathrm{G})$ transitions. The absorption band in the infrared is associated with the electronic transitions from the ${ }^{4} \mathrm{~A}_{2}(\mathrm{~F})$ ground-state to the ${ }^{4} \mathrm{~T}_{1}(\mathrm{~F})$ excited multiplet. This is actually the band intended to be used for Q-switching of erbium lasers. The above-mentioned spectral changes indicate an appearance of undistorted tetrahedrally coordinated $\mathrm{Co}^{2+}$ ions in $\mathrm{ZnO}$ nanocrystals at the expense of the $\mathrm{Co}^{2+}$ ions located in the initial glass. They are clearly connected with the $\mathrm{ZnO}$ crystallization and entering the $\mathrm{Co}^{2+}$ ions in its structure in the positions of $\mathrm{Zn}^{2+}$ ions $[15,16,30]$. The increase of fraction of $\mathrm{ZnO}$ is accompanied by the increase of absorption of tetrahedrally coordinated $\mathrm{Co}^{2+}$ ions. However, a careful comparison of the absorption spectra of the Co: $\mathrm{ZnO}$ based GCs and $\mathrm{Zn}_{1-x} \mathrm{Co}_{x} \mathrm{O}$ powders [31] revealed that there is still an inflection at $\sim 525 \mathrm{~nm}$ in the spectrum of the GCs and the intensity of the band at $\sim 565 \mathrm{~nm}$ is lower that in the spectrum of the $\mathrm{Zn}_{1-x} \mathrm{Co}_{x} \mathrm{O}$ powders. These facts led us to the conclusion that after the proposed heat-treatments at $680-700{ }^{\circ} \mathrm{C}$, some portion of $\mathrm{Co}^{2+}$ ions still remains in the residual glass phase.

In the inset of figure 4 , we present a comparison of the absorption related to the ${ }^{4} \mathrm{~A}_{2}\left({ }^{4} \mathrm{~F}\right) \rightarrow{ }^{4} \mathrm{~T}_{1}\left({ }^{4} \mathrm{~F}\right)$ transition of $\mathrm{Co}^{2+}$ ions in the GCs with $\mathrm{Co}: \mathrm{ZnO}$ nanocrystals prepared by the heat-treatment at $700{ }^{\circ} \mathrm{C}$, GCs containing $\mathrm{Co}: \mathrm{MgAl}_{2} \mathrm{O}_{4}$ spinel nanocrystals and $\mathrm{Co}: \mathrm{MgAl}_{2} \mathrm{O}_{4}$ single crystals. Then, we determined the long-wavelength edge $\lambda_{\text {th }}$ of this absorption band (corresponding to the half intensity of the peak absorption).
For the GCs based on Co: $\mathrm{ZnO}$ nanocrystals, $\lambda_{\text {th }}=1.73 \mu \mathrm{m}$ and it is only $1.58 \mu \mathrm{m}$ for $\mathrm{Co}: \mathrm{MgAl}_{2} \mathrm{O}_{4}$ single crystals and $1.63 \mu \mathrm{m}$ for $\mathrm{Co}: \mathrm{MgAl}_{2} \mathrm{O}_{4}$ based GCs. Thus, the proposed GCs are promising for passive Q-switching of erbium lasers emitting in the $1.6-1.7 \mu \mathrm{m}$ spectral range.

\subsection{Absorption saturation}

For the absorption saturation experiment, the GC sample doped with $0.1 \mathrm{wt} \% \mathrm{CoO}$ and containing $\mathrm{Co}^{2+}: \mathrm{ZnO}$ nanocrystals was prepared at $700{ }^{\circ} \mathrm{C}$ for $24 \mathrm{~h}$. It was $3.9 \mathrm{~mm}$ thick $\left(T_{0}=42 \%\right.$ at $\left.1.54 \mu \mathrm{m} ; \alpha_{0}=2.3 \mathrm{~cm}^{-1}\right)$. The sample was polished to laser quality and it was remained uncoated.

Absorption saturation was performed with the Z-scan technique. The excitation beam was generated by a flashlamppumped $\mathrm{Er}^{3+}, \mathrm{Yb}^{3+}$ :glass laser passively Q-switched by a $\mathrm{Co}^{2+}: \mathrm{MgAl}_{2} \mathrm{O}_{4}$ single crystal SA (pulse energy: $\sim 2 \mathrm{~mJ}$, pulse duration: $70 \mathrm{~ns}, \mathrm{TEM}_{00}$ output). The output of this laser was focused by a spherical lens $(f=35 \mathrm{~mm})$ to a $\sim 80 \mu \mathrm{m}$ spot. The studied sample was translated along the beam in the longitudinal direction thus providing a variation of the incident fluence in the range of $0.4-12.0 \mathrm{~J} \mathrm{~cm}^{-2}$.

The radius of the laser beam $w$ with respect to the axial coordinate $(z)$ was measured with a CCD-camera. The incident pulse energy $E_{\text {inc }}$ was measured with an Ophir PE-10C energy meter with a precision of $0.1 \mathrm{~mJ}$. The incident fluence on the sample was then calculated as $F_{\text {inc }}(z)=2 E_{\text {ind }}$ $\left[\pi w(z)^{2}\right]$ (the factor 2 emerges from the consideration of Gaussian spatial profile of the pump laser beam). After insertion of the sample, the pulse energy of the transmitted pump beam $E_{\text {trans }}(z)$ was measured. The internal power-dependent transmission of the studied sample was then determined as $T(z)=X Y\left[E_{\text {trans }}(z) / E_{\text {inc }}\right]$ where $X$ is the correction factor due to the Fresnel losses and $Y$ is the calibration constant. To calibrate the set-up, we used a polished plate from an undoped silicate glass showing no absorption saturation. Then, taking into account the dependence $F_{\text {inc }}(z)$, the experimental curve $T\left(F_{\text {inc }}\right)$ was achieved.

The experimental data on $T\left(F_{\text {inc }}\right)$ were modeled with a slow SA model because the characteristic recovery time for $\mathrm{Co}^{2+}$ ions is typically few hundreds of ns that is much shorter than the duration of the excitation pulse (in our case, $\sim 70 \mathrm{~ns}$ ). As the thickness of the studied sample was relatively long $(t \sim 3 \mathrm{~mm})$, it cannot be considered as a thin SA. Thus, the following formula was used $[12,13]$ :

$$
\frac{\mathrm{d} F}{\mathrm{~d} z}=-\alpha_{0} F_{\mathrm{S}}\left[(1-\gamma)\left(1-\mathrm{e}^{-F / F_{\mathrm{S}}}\right)+\gamma \frac{F}{F_{\mathrm{S}}}\right] .
$$

Here, $z$ denotes the axial coordinate inside the SA, $F_{\mathrm{S}}=h \nu / \sigma_{\mathrm{GSA}}$ is the saturation fluence of the studied material; $\gamma$ is the saturation contrast that is equal to $\sigma_{\mathrm{ESA}} / \sigma_{\mathrm{GSA}} ; h$ is the Planck constant, $\nu=c / \lambda$ is the light frequency, $c$ is the speed of light; $\sigma_{\mathrm{ESA}}$ and $\sigma_{\mathrm{GSA}}$ are the cross-sections for the excitedand ground-state absorption (ESA and GSA) for the $\mathrm{Co}^{2+}$ ions, respectively. In equation (2), $F_{\mathrm{S}}$ and $\gamma$ are free parameters that were varied. For each incident fluence $F_{\text {inc }}$, equation (2) was solved for $z=0 \ldots t$ and the theoretical transmitted energy 


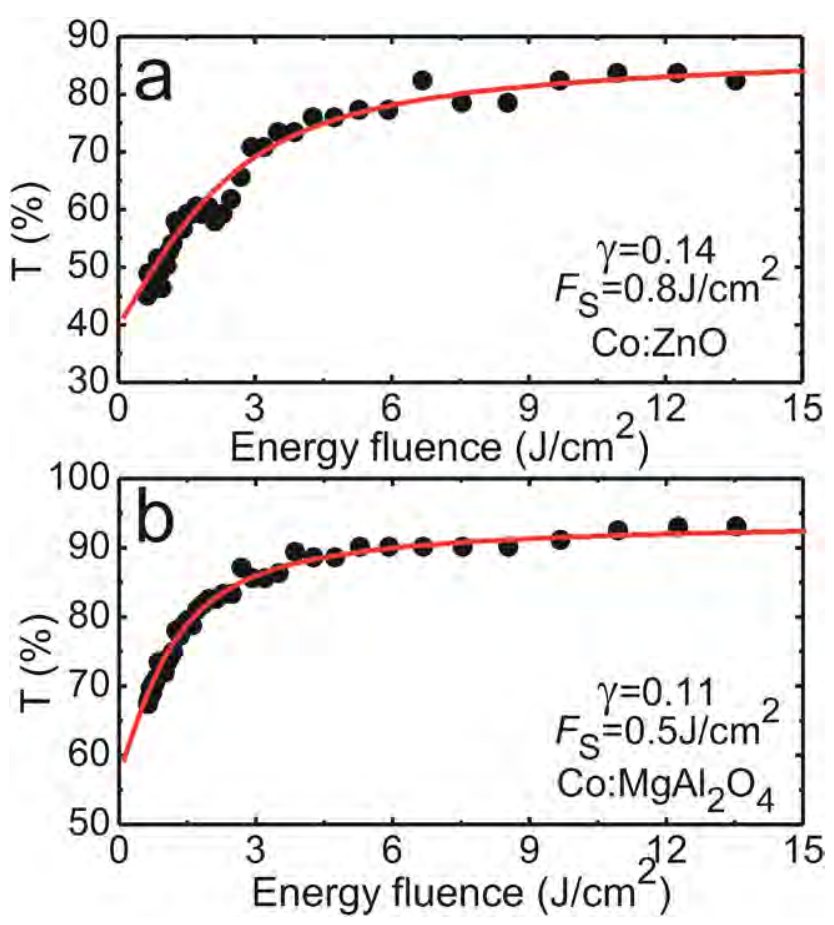

Figure 5. Absorption saturation curves for (a) Co: $\mathrm{ZnO}$-based GC doped with $0.1 \mathrm{wt} \% \mathrm{CoO}$ prepared at $700{ }^{\circ} \mathrm{C}$ for $24 \mathrm{~h}$ and (b) $\mathrm{Co}: \mathrm{MgAl}_{2} \mathrm{O}_{4}$ single crystal.

fluence $F_{\text {trans }}^{\prime}$ was found. Then, the theoretical transmission of the SA $T^{\prime}\left(F_{\text {inc }}\right)=F_{\text {trans }}^{\prime} / F_{\text {inc }}$ was determined. Finally, the experimental curve $T\left(F_{\text {inc }}\right)$ was fitted with the theoretical one, $T^{\prime}\left(F_{\text {inc }}\right)$, yielding $F_{\mathrm{S}}$ and $\gamma$ parameters.

For the GC containing $\mathrm{Co}: \mathrm{ZnO}$ nanocrystals, the best fitting parameters for the absorption saturation curve are $F_{\mathrm{S}}=0.8 \pm 0.1 \mathrm{Jcm}^{-2}$ and $\gamma=0.14 \pm 0.02$, figure 5(a), which are close to the same parameters determined for the $\mathrm{Co}: \mathrm{MgAl}_{2} \mathrm{O}_{4}$ single crystal, $F_{\mathrm{S}}=0.5 \pm 0.1 \mathrm{Jcm}^{-2}$ and $\gamma=0.11 \pm 0.02$, see figure $5(\mathrm{~b})$. The ground-state absorption cross-section $\sigma_{\mathrm{GSA}}$ for the $\mathrm{Co}^{2+}$ ions in the $\mathrm{ZnO}$ nanocrystals is $\sim 1.7 \pm 0.2 \times 10^{-19} \mathrm{~cm}^{2}$ at $1.54 \mu \mathrm{m}$; and the value for the excited-state absorption cross-section is $\sigma_{\mathrm{ESA}}=0.24 \pm 0.05$ $\times 10^{-19} \mathrm{~cm}^{2}$. The laser damage threshold for the glass-ceramics with $\mathrm{Co}: \mathrm{ZnO}$ nanocrystals was determined to be as high as $\sim 14 \pm 2 \mathrm{Jcm}^{-2}$.

\subsection{Recovery time}

To measure the characteristic recovery time of the initial absorption of the $\mathrm{Co}^{2+}$ ions $(\tau)$, we employed the pumpprobe method. The studied sample was excited by the output of a flashlamp-pumped $\mathrm{Er}^{3+}, \mathrm{Yb}^{3+}$ :glass laser passively Q-switched by a $\mathrm{Co}^{2+}: \mathrm{MgAl}_{2} \mathrm{O}_{4}$ single crystal SA (pulse energy: $4 \mathrm{~mJ}$, pulse duration: $\sim 70 \mathrm{~ns}$, multimode output). The pump beam was focused onto the sample to a spot of $\sim 500 \mu \mathrm{m}$ in diameter providing a maximum pump fluence of $\sim 10 \mathrm{Jcm}^{-2}$ that corresponded to a near-complete bleaching of the sample but was slightly below the laser damage threshold. The pump wavelength was $\sim 1.54 \mu \mathrm{m}$ that corresponded to the ${ }^{4} \mathrm{~A}_{2}\left({ }^{4} \mathrm{~F}\right) \rightarrow{ }^{4} \mathrm{~T}_{1}\left({ }^{4} \mathrm{~F}\right)$ transition of the $\mathrm{Co}^{2+}$ ions in tetrahedral sites. As a probe beam, we used the output of

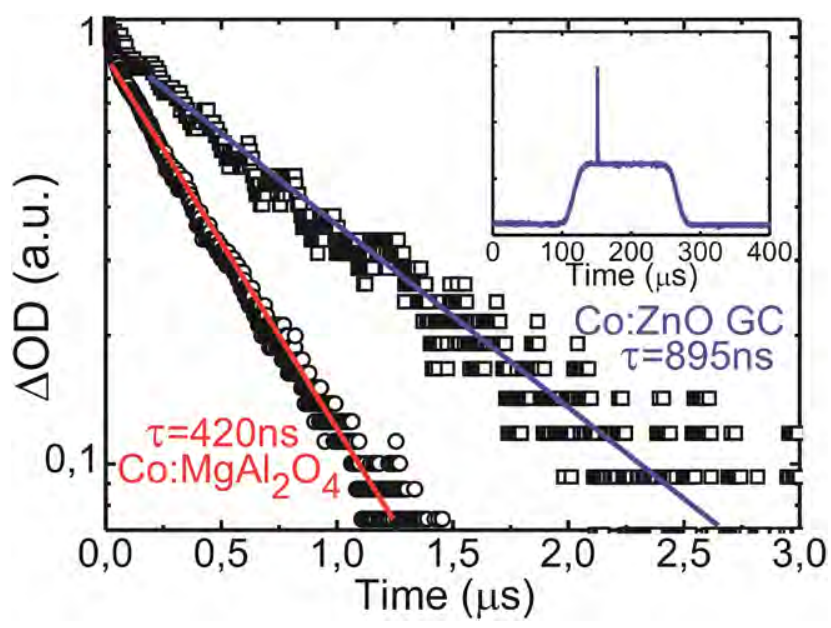

Figure 6. Semi-logarithmic plot of the differential optical density $\triangle \mathrm{OD}$ as a function of time for $\mathrm{GC}$ with $\mathrm{Co}: \mathrm{ZnO}$ nanocrystals and Co: $\mathrm{MgAl}_{2} \mathrm{O}_{4}$ single crystal, symbols represent the experimental data, lines are their modeling with a monoexponential law for the extraction of the recovery time $(\tau)$, inset shows the typical as-measured oscilloscope trace.

a continuous-wave $\mathrm{He}-\mathrm{Ne}$ laser $(632.8 \mathrm{~nm})$ that was modulated by a mechanical chopper (frequency: $550 \mathrm{~Hz}$, pulse duration: $160 \mu \mathrm{s})$. The probe wavelength corresponded to the ${ }^{4} \mathrm{~A}_{2}\left({ }^{4} \mathrm{~F}\right) \rightarrow{ }^{4} \mathrm{~T}_{1}\left({ }^{4} \mathrm{P}\right)$ transition for tetrahedrally coordinated $\mathrm{Co}^{2+}$ ions. Thus, we were able to monitor the recovery of the initial population of the ${ }^{4} \mathrm{~A}_{2}\left({ }^{4} \mathrm{~F}\right)$ ground-state that determines the $\tau$ value. In addition, the large spectral separation of the pump and probe beams simplified their detection. To detect the probe beam, a fast Hamamatsu C5460 photodetector (response time, $<40 \mathrm{~ns}$ ) and a $500 \mathrm{MHz}$ Tektronix TDS3052B digital oscilloscope were used.

As a result of the ground-state depletion of the $\mathrm{Co}^{2+}$ ions by the pump pulse, the transmission of the probe beam temporarily increased. The differential absorption was then determined. It reads $\Delta \mathrm{OD}(t)=\ln \left[T(t) / T_{0}\right]$, where $T_{0}$ is the initial (non-saturated) transmission of the sample, and $T(t)$ is its transmission at a time $t$ after the end of the pump pulse. The recovery time $\tau$ was then deduced by fitting the curve to an exponential decay in the form:

$$
\Delta \mathrm{OD}(t)=\Delta \mathrm{OD}_{\max } \exp (-t / \tau) .
$$

For the recovery time measurements, we used the same sample as for the absorption saturation experiment. The results are illustrated in figure 6 . The kinetics of the differential absorption is plotted in a semi-log scale. It is clearly linear, the recovery time $\tau=890 \pm 10 \mathrm{~ns}$ for the GC heattreated at $700{ }^{\circ} \mathrm{C}$ for $24 \mathrm{~h}$. This value is $\sim 2$ times longer than that for the $\mathrm{Co}: \mathrm{MgAl}_{2} \mathrm{O}_{4}$ single crystal studied for comparison ( $\tau=420 \mathrm{~ns}$ ). However, this value is short enough to ensure generation of ns Q-switched pulses for erbium lasers operating at frequencies from few $\mathrm{Hz}$ to few $\mathrm{kHz}$.

\subsection{Q-switching performance}

The studied glass-ceramics were tested for Q-switching of an erbium laser. A rod-shaped laser element (diameter: $1.6 \mathrm{~mm}$, 

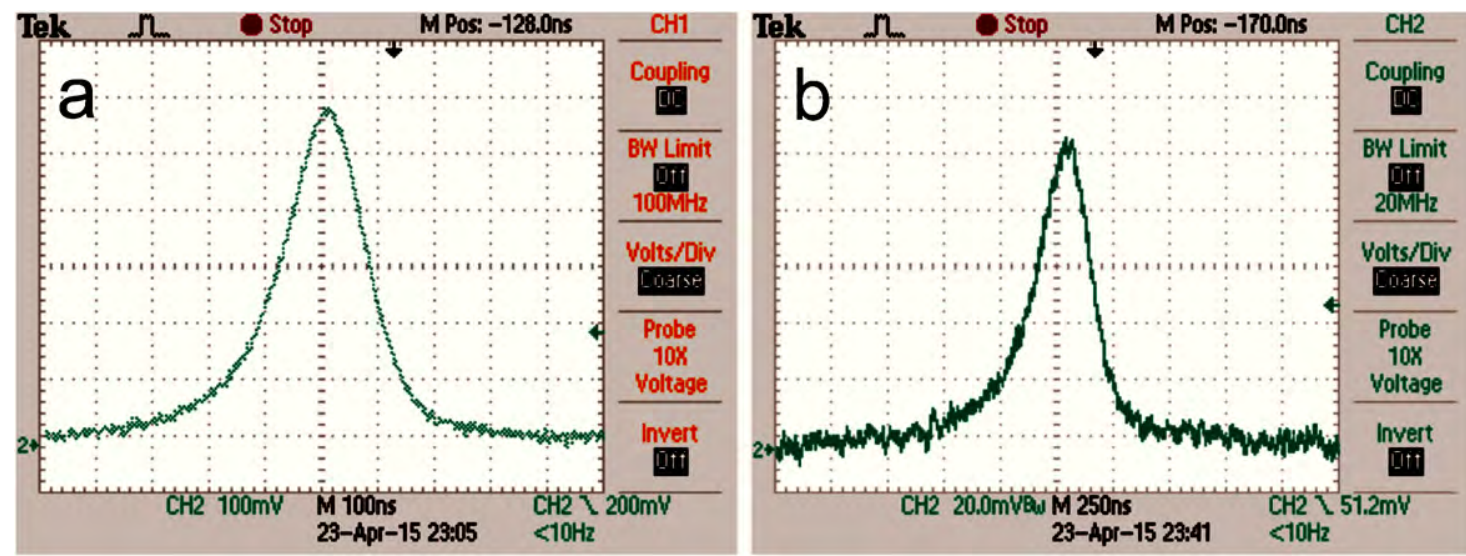

Figure 7. Oscilloscope traces of a single Q-switched pulse for the Er,Yb: glass laser when using Co:ZnO based glass-ceramics as a SA: left image- GC heat-treated at $680{ }^{\circ} \mathrm{C}$ for $18 \mathrm{~h}$, right image- GC heat-treated at $700{ }^{\circ} \mathrm{C}$ for $4 \mathrm{~h}$.

Table 1. Output characteristics ${ }^{\mathrm{a}}$ of the diode-pumped Er,Yb:glass laser passively Q-switched by the developed glass-ceramics based on $\mathrm{Co}: \mathrm{ZnO}$ nanocrystals.

\begin{tabular}{lllll}
\hline Heat-treatment & $T_{0}(\%)$ & $E_{\text {out }}(\mathrm{mJ})$ & $\Delta \tau(\mathrm{ns})$ & $\eta_{\text {conv }}(\%)$ \\
\hline $680^{\circ} \mathrm{C} / 18 \mathrm{~h}$ & 91.5 & 0.37 & 100 & 2.2 \\
$700^{\circ} \mathrm{C} / 4 \mathrm{~h}$ & 89.7 & 0.24 & 250 & 0.8 \\
\hline
\end{tabular}

${ }^{a} E_{\text {out }}$-output pulse energy, $\Delta \tau$-pulse duration, $\eta_{\text {conv }}-\mathrm{Q}$-switching conversion efficiency.

length: $24 \mathrm{~mm})$ was prepared from a commercial $\left(\mathrm{Er}^{3+}, \mathrm{Yb}^{3+}\right)$ codoped phosphate glass. Both of its surfaces were antireflection (AR) coated for the wavelength $\sim 1.54 \mu \mathrm{m}$. The concentrations of $\mathrm{Er}^{3+}$ and $\mathrm{Yb}^{3+}$ ions were $0.27 \times 10^{20}$ and $2.5 \times 10^{21} \mathrm{atcm}^{-3}$, respectively. The rod was side-pumped by a passively-cooled stack of three $70 \mathrm{~W}$ InGaAs laser diode bars emitting at $\sim 940 \mathrm{~nm}$. The duration of the pump pulses was electrically controlled to be $\sim 5 \mathrm{~ms}$, with a pulse repetition frequency of $1 \mathrm{~Hz}$.

The back mirror of the laser cavity was concave (radius of curvature: $1.5 \mathrm{~m}$ ) and highly reflective $(\mathrm{HR})$ at $\sim 1.54 \mu \mathrm{m}$. The flat output coupler (OC) had a transmission of $T_{\mathrm{OC}}=13 \%$. The geometrical cavity length was $65 \mathrm{~mm}$. The SAs were prepared from the glass-ceramics doped with $0.05 \mathrm{wt} \% \mathrm{CoO}$ and heattreated at $680{ }^{\circ} \mathrm{C}$ and $700{ }^{\circ} \mathrm{C}$, see table 1 . Both surfaces of the SAs were AR-coated for the wavelength $\sim 1.54 \mu \mathrm{m}$. The SA was inserted into the laser cavity at normal incidence. The initial transmission of the SAs at $1.54 \mu \mathrm{m} T_{0}$ was 98.7 and $91.5 \%$, respectively. The SA was positioned between the laser rod and the OC. The radius of the laser mode on the SA was $\sim 150 \mu \mathrm{m}$.

The output characteristics of the Er,Yb:glass lasers passively Q-switched with the developed GCs based on the $\mathrm{Co:} \mathrm{ZnO}$ nanocrystals are shown in table 1 . The maximum pulse energy for a single Q-switching pulse $E_{\text {out }}$ was $0.37 \mathrm{~mJ}$ for the SA made of the GC prepared by the heat-treatment at $680{ }^{\circ} \mathrm{C}$ for $18 \mathrm{~h}$. This corresponded to a pulse duration $\Delta \tau=100 \mathrm{~ns}$ (determined as a full width at half maximum, FWHM). The temporal shape of the Q-switching pulse was close to a Gaussian one (see figure 7). The conversion efficiency with respect to the free-running mode (when the SA was removed from the cavity) was $2.2 \%$; the corresponding pump pulse energy was $0.93 \mathrm{~J}$. The use of the SA obtained by the heat-treatment at $700{ }^{\circ} \mathrm{C}$ for $4 \mathrm{~h}$ provided much longer pulses $(\Delta \tau=250 \mathrm{~ns})$ with a lower pulse energy $\left(E_{\text {out }}=0.24\right.$ $\mathrm{mJ})$. This is attributed mainly to a lower fraction of Co: $\mathrm{ZnO}$ nanocrystals with $\mathrm{Co}^{2+}$ ions in tetrahedral sites as compared with the samples prepared at $680{ }^{\circ} \mathrm{C}$ for $18 \mathrm{~h}$ (see figure 1).

\section{Conclusions}

XRD, Raman and TEM studies and optical spectroscopy of heat-treated glasses of the $\mathrm{K}_{2} \mathrm{O}-\mathrm{ZnO}-\mathrm{Al}_{2} \mathrm{O}_{3}-\mathrm{SiO}_{2}$ system doped with $\mathrm{CoO}$ revealed crystallization of $\mathrm{Co}^{2+}: \mathrm{ZnO}$ nanocrystals of $\sim 11 \mathrm{~nm}$ in size in the residual potassium aluminosilicate glass and entering the $\mathrm{Co}^{2+}$ ions into these nanocrystals in the tetrahedral $\mathrm{Zn}^{2+}$ positions. The feature of the developed $\mathrm{GC}$ is the red-shift of the absorption band related to the ${ }^{4} \mathrm{~A}_{2}\left({ }^{4} \mathrm{~F}\right) \rightarrow{ }^{4} \mathrm{~T}_{1}\left({ }^{4} \mathrm{~F}\right)$ transition of $\mathrm{Co}^{2+}$ ions up to $\sim 1.73 \mu \mathrm{m}$. Saturation of absorption is demonstrated within this band (at $1.54 \mu \mathrm{m})$, with a saturation fluence $F_{\mathrm{s}}=0.8 \pm 0.1 \mathrm{Jcm}^{-2}$ and recovery time of $890 \pm 10 \mathrm{~ns}$. The synthesized GC is used to demonstrate passive Q-switching of a diode-pumped Er,Yb:glass laser that generated $0.37 \mathrm{~mJ} / 100 \mathrm{~ns}$ pulses at $1.54 \mu \mathrm{m}$. GCs based on $\mathrm{Co}^{2+}: \mathrm{ZnO}$ nanocrystals are promising as a long-wavelength saturable absorber for crystalline erbium lasers emitting at $1.6-1.7 \mu \mathrm{m}$.

\section{Acknowledgments}

O S Dymshits, A A Zhilin, D V Shemchuk and M Ya Tsenter express their gratitude to the RFBR (Grant 16-03-01130) for partial support of this work. This work was also partially supported by the Government of Russian Federation (Grant 074-U01).

\section{References}

[1] Karlsson G, Laurell F, Tellefsen J, Denker B, Galagan B, Osiko V and Sverchkov S 2002 Appl. Phys. B 75 41-6

[2] Tolstik N A, Kurilchik S V, Kisel V E, Kuleshov N V, Maltsev V V, Pilipenko O V, Koporulina E V and Leonyuk N I 2007 Opt. Lett. 32 3233-5 
[3] Gorbachenya K N, Kisel V E, Yasukevich A S, Maltsev V V, Leonyuk N I and Kuleshov N V 2013 Opt. Lett. 38 2246-8

[4] Chen Y J, Lin Y F, Huang J H, Gong X H, Luo Z D and Huang Y D 2013 Laser Phys. 23095801

[5] Loiko P A, Filippov V V, Kuleshov N V, Leonyuk N I, Maltsev V V and Yumashev K V 2014 Appl. Phys. B $117577-83$

[6] Mlynczak J and Belghachem N 2015 Laser Phys. Lett. 12045803

[7] Karlsson G, Pasiskevicius V, Laurell F, Tellefsen J A Denker B, Galagan B I, Osiko V V and Sverchkov S 2000 Appl. Opt. 39 6188-92

[8] Kisel V E, Gorbachenya K N, Yasukevich A S, Ivashko A M, Kuleshov N V, Maltsev V V and Leonyuk N I 2012 Opt. Lett. 37 2745-7

[9] Ter-Gabrielyan N, Fromzel V, Lukasiewicz T, Ryba-Romanowski W and Dubinskii M 2011 Opt. Lett. 36 1218-20

[10] Yang X F, Shen D Y, Zhao T, Chen H, Zhou J, Li J, Kou H M and Pan Y B 2011 Laser Phys. 21 1013-6

[11] Kim J W, Shen D Y, Sahu J K and Clarkson W A 2008 Opt. Express 16 5807-12

[12] Volk Yu V, Denisov I A, Malyarevich A M, Yumashev K V, Dymshits O S, Shashkin A V, Zhilin A A, Kang U and Lee K-H 2004 Appl. Opt. 43 682-7

[13] Denisov I A, Volk Yu V, Malyarevich A M, Yumashev K V, Dymshits O S, Zhilin A A, Kang U and Lee K-H 2003 J. Appl. Phys. 93 3827-31

[14] Loiko P A et al 2015 Laser Phys. Lett. 12035803

[15] Pinckney L R 2006 Phys. Chem. Glass. 47 127-30
[16] Alekseeva I P, Dymshits O S, Zhilin A A, Zapalova S S and Shemchuk D V 2006 J. Opt. Technol. $81723-8$

[17] Lipson H and Steeple H 1970 Interpretation of X-Ray Powder Patterns (London: Macmillan)

[18] Du X, Zhang H, Cheng C, Zhou S, Zhang F, Yu Y, Dong G and Qiu J 2014 Opt. Express 22 17908-14

[19] Mahmood K, Park S B and Sung H J 2014 J. Mater. Chem. C $13138-49$

[20] Arguello C A, Rousseau D L and Porto S P S 1969 Phys. Rev. 181 1351-63

[21] Ovsyuk N N and Goryainov S V 2006 JETP Lett. 83 109-12

[22] McMillan P, Piriou B and Navrotsky A 1982 Geochim. Cosmochim. Acta 46 2021-37

[23] Matson D W, Sarma S K and Fhilpotts J A 1986 Am. Mineral. 71 694-704

[24] Kang U, Dymshits O S, Zhilin A A, Chuvaeva T I and Petrovsky G T 1996 J. Non-Cryst. Solids 204 151-7

[25] Alekseeva I, Baranov A, Dymshits O, Ermakov V, Golubkov V, Tsenter M and Zhilin A 2011 J. Non-Cryst. Solids 357 3928-39

[26] Bates T 1962 Modern Aspects of the Vitreous State ed J D Mackenzie (London: Butterworths) pp 195-254

[27] Bamford C R 1997 Colour Generation and Control in Glass (Amsterdam: Elsevier)

[28] Hunault M, Calas G, Galoisy L, Lelong G and Newville M 2014 J. Am. Ceram. Soc. 97 60-2

[29] Keppler H and Bagdassarov N 1999 Chem. Geol. 158 105-15

[30] Peng Y Z, Liew T, Song W D, An C W, Teo K L and Chong T C 2005 J. Supercond. 18 97-103

[31] Guo S, Zhang X, Huang Y, Li Y and Du Z 2008 Chem. Phys. Lett. $45982-4$ 